\title{
Is Doppler ultrasound of additional value to gray-scale ultrasound in differentiating malignant and benign thyroid nodules?
}

Pedro Weslley Rosario',2, Alexandre Lemos da Silva', Michelle Aparecida Ribeiro Borges ${ }^{3}$, Maria Regina Calsolari ${ }^{1,2}$

\section{SUMMARY}

The objective of this study was to evaluate whether Doppler ultrasound (DUS) is of additional value to gray-scale ultrasound (GSUS) in predicting the benign or malignant nature of thyroid nodules. A total of 1,502 solid thyroid nodules $\geq 10 \mathrm{~mm}$ were evaluated. Suspicious vascularity (predominantly or exclusively central blood flow) was observed in only $5 \%$ of the nodules. This finding showed $96 \%$ specificity, but only $15 \%$ sensitivity. GSUS alone showed sensitivity and specificity of $88.7 \%$ and $68.2 \%$, respectively, which did not improve with the addition of DUS (sensitivity of $89.4 \%$ and specificity of $66.4 \%)$. In non-suspicious nodules on GSUS, the type of vascularity on DUS did not modify the risk of malignancy, which was low. In suspicious nodules on GSUS, suspicious vascularity on DUS increased the risk of malignancy, but non-suspicious vascularity did not reduce this risk. DUS provided no additional value to GSUS in predicting the benign or malignant nature of thyroid nodules. Arch Endocrinol Metab. 2015;59(1):79-83
${ }_{1}^{1}$ Postgraduation Program, Santa Casa de Belo Horizonte, Belo Horizonte, MG, Brazil

${ }^{2}$ Endocrinology Service, Santa Casa de Belo Horizonte, Belo Horizonte, MG, Brazil

${ }^{3}$ Universidade Estadual de Montes Claros (Unimontes).

Montes Claros, MG, Brazil

Correspondence to:

Pedro Weslley Rosario

Instituto de Ensino e Pesquisa, Santa Casa de Belo Horizonte

Rua Domingos Vieira, 590

30150-240 - Belo Horizonte

MG, Brazil

pedrowsrosario@gmail.com

Received on Mar/24/2014 Accepted on May/29/2014

DOI: 10.1590/2359-3997000000014

\section{INTRODUCTION}

$\mathrm{T}$ he current indications for fine-needle aspiration (FNA) of thyroid nodules $<10 \mathrm{~mm}$ are highly selective (1-7). FNA is also not necessary in the case of autonomous or cystic nodules $\geq 10 \mathrm{~mm}$. In the remaining cases, ultrasonographic characteristics of the nodule (composition, echogenicity, shape, margins, halo, calcifications) are important for the indication of FNA and for estimating the risk of malignancy. Nodule vascularity has also been proposed to be of diagnostic value, but many authors question this proposal $(3,4,8-11)$.

In addition to the controversy regarding the use of Doppler US for the differentiation of benign and malignant nodules, there is no consensus which type of vascularity would be considered suspicious of malignancy. Some organization such as the American Thyroid Association (2), American Association of Clinical Endocrinologists and European Thyroid Association (12), European Society for Medical Oncology (5), and National Comprehensive Cancer Network (7) consider "increased intranodal vascularity" as suspicious, without requiring that vascularity is predomi- nantly or exclusively intranodal. Others such as the Society of Radiologists in Ultrasound (1), French Society of Endocrinology (13), and Brazilian Society of Endocrinology (6) propose only "predominantly or exclusively central" blood flow to be defined as suspicious.

Finally, even when vascularity is taken into consideration, other ultrasonographic characteristics of the nodule continue to be important, i.e., Doppler US does not replace gray-scale ultrasound (GSUS). It is therefore important to know whether (i) an apparently benign nodule on GSUS becomes suspicious when Doppler US reveals suspicious vascularity and the probability of the nodule being benign increases when Doppler US is also not suspicious; (ii) a suspicious nodule on GSUS is no longer suspicious when Doppler US is not suspicious and its risk of malignancy increases when Doppler US is also suspicious.

The objective of the present study was to determine whether Doppler US is of additional diagnostic value to GSUS in predicting the nature of solid thyroid nodules $\geq 10 \mathrm{~mm}$. 


\section{SUBJECTS AND METHODS}

Design

Prospective study.

\section{Patients}

Consecutive patients who had at least one thyroid nodule $\geq 10 \mathrm{~mm}$ were selected. The following nodules $\geq$ $10 \mathrm{~mm}$ were excluded: cystic, complex (mixed) or hot nodules on ${ }^{131}$ I scintigraphy (performed on patients with low TSH). Thus, nontoxic solid or predominantly solid nodules $\geq 10 \mathrm{~mm}$ were included. The study was approved by the local Research Ethics Committee.

\section{Doppler US}

Ultrasound was performed with a linear multifrequency 12-MHz transducer for morphological analysis (grayscale) and for power Doppler evaluation. Ultrasound was performed by three experienced radiologists. Suspicious ultrasonographic findings were microcalcifications, hypoechogenicity, microlobulation or irregular margins, and a taller-than-wide shape (being greater in the anteroposterior dimension than in the transverse dimension) (1). The type of blood flow of all thyroid nodules was evaluated before US-guided FNA. Using the first classification, three types of vascularity were identified (14): type 0 , no vascularity - defined as no flow at the periphery or inside the nodule; type 1, peripheral vascularity - defined as flow only at the periphery of the nodule, and type 2 , intranodular vascularity - defined as flow inside the nodule regardless of flow at the periphery. Using the second classification, four types of vascularity were identified (adapted from 15,16): type 0 , no vascularity; type 1 , peripheral vascularity; type 2 , peripheral and intranodular vascularity; type 3 , exclusively or predominantly intranodular vascularity.

\section{FNA}

FNA was performed with a 22-gauge needle and a 5- or $10-\mathrm{mL}$ syringe and was guided by US. The smears were analyzed by pathologists experienced in thyroid pathology. The cytological diagnosis was classified as benign, indeterminate (follicular lesion of undetermined significance, atypia of undetermined significance, suspicious of or follicular neoplasm), suspicious of malignancy or malignant, or inadequate. All patients were referred for surgery, except for those with benign cytology. Only the cytological or histological diagnosis of the thyroid nodule included in the study was considered for analysis.

\section{Statistical analysis}

Fisher's exact test or the $\chi^{2}$ test was used to detect differences in the proportion of cases. A p-value of less than 0.05 was considered to be significant.

\section{RESULTS}

There were 1,106 eligible patients (902 women; age range: 9-83 years, median of 48 years) with 1,502 solid nodules $\geq 10 \mathrm{~mm}$ and all of them underwent FNA. Cytology was benign in 1,135 nodules (75.5\%). A cytology result classified as malignant or suspicious of malignancy, indeterminate, or inadequate was observed in $87(5.6 \%)$, $190(12.6 \%)$, and $90(6 \%)$ nodules, respectively. Since 10 patients with 12 nodules refused or had contraindications to thyroidectomy, histology was available for 355 of 367 nodules with non-benign cytology. One hundred sixty of these 355 nodules were malignant. The 10 patients with indeterminate $(\mathrm{n}=3)$ or inadequate $(\mathrm{n}=$ 7) cytology and without available histology were at low clinical risk of malignancy $(2-7,12,13,17)$, and the nodules showed no growth after 24 months of follow-up.

Considering the first classification, suspicious vascularity (type 2) was observed in $64.6 \%$ of the nodules. This findings showed $70 \%$ sensitivity, but only $36 \%$ specificity. The frequencies of nodules without apparent flow, with exclusively peripheral flow, or with intranodal flow did not differ between benign and malignant lesions (Table 1). In addition, the risk of malignancy did not differ according to the type of vascularity (Table 1 ).

Table 1. Distribution of the type of vascularity (first classification) on Doppler US in benign and malignant nodules and probability of malignancy according to vascularity

\begin{tabular}{lccc}
\hline $\begin{array}{l}\text { Type of } \\
\text { vascularity }\end{array}$ & Benign nodules & $\begin{array}{c}\text { Malignant } \\
\text { nodules }\end{array}$ & $\begin{array}{c}\text { Probability of } \\
\text { malignancy }\end{array}$ \\
\hline Type 0 & $82(6.1 \%)$ & $8(5 \%)$ & $8 / 90(8.9 \%)$ \\
Type 1 & $401(29.9 \%)$ & $40(25 \%)$ & $40 / 441(9 \%)$ \\
Type 2 & $859(64 \%)$ & $112(70 \%)$ & $112 / 971(11.5 \%)$ \\
& 1,342 & 160 & $160 / 1502(10.6 \%)$ \\
\hline
\end{tabular}

Using the second classification, suspicious vascularity (type 3 ) was seen in only $5 \%$ of the nodules. This finding showed $96 \%$ specificity, but only $15 \%$ sensitivity. The initial probability of malignancy did not decrease in the absence of predominantly or exclusively intrano- 
dal vascularity, but increased significantly [from 10.6\% to $31.6 \%(\mathrm{p}<0.001)]$ in the presence of this vascularity (Table 2).

Table 2. Distribution of the type of vascularity (second classification) on Doppler US in benign and malignant nodules and probability of malignancy according to vascularity

\begin{tabular}{lccc}
\hline $\begin{array}{l}\text { Type of } \\
\text { vascularity }\end{array}$ & Benign nodules & $\begin{array}{c}\text { Malignant } \\
\text { nodules }\end{array}$ & $\begin{array}{c}\text { Probability of } \\
\text { malignancy }\end{array}$ \\
\hline Type 0 & $82(6.1 \%)$ & $8(5 \%)$ & $8 / 90(8.9 \%)$ \\
Type 1 & $401(29.9 \%)$ & $40(25 \%)$ & $40 / 441(9 \%)$ \\
Type 2 & $807(60.1 \%)$ & $88(55 \%)$ & $88 / 895(9.8 \%)$ \\
Type 3 & $52(3.9 \%)$ & $24(15 \%)$ & $24 / 76(31.6 \%)$ \\
& 1,342 & 160 & $160 / 1,502(10.6 \%)$ \\
\hline
\end{tabular}

Next, it was determined whether Doppler US using the second classification would be useful in addition to GSUS. The sensitivity and specificity of GSUS alone were $88.7 \%$ and $68.2 \%$, respectively. Considering vascularity type 3 as "suspicious" and types 0-2 as "non-suspicious", the addition of Doppler US did not change the sensitivity $(89.4 \%)$ or specificity $(66.4 \%)$ of GSUS. In the case of non-suspicious nodules on GSUS, Doppler US did not change the risk of malignancy, which was low irrespective of the type of vascularity (Table 3 ). In the case of suspicious nodules on GSUS, vascularity type 3 found in only $9 \%$ of these nodules increased the risk of malignancy [from $25 \%$ to $45 \%(\mathrm{p}<0.002)$ ], but the other types of vascularity (types 0-2) did not reduce the probability of malignancy (Table 3 ).

Table 3. Probability of malignancy in suspicious and non-suspicious nodules on gray-scale ultrasound (GSUS) combined with type of vascularity on Doppler US (second classification)

\begin{tabular}{lcc}
\hline $\begin{array}{l}\text { Type of } \\
\text { vascularity }\end{array}$ & $\begin{array}{c}\text { Non-suspicious nodules } \\
\text { on GSUS }\end{array}$ & $\begin{array}{c}\text { Suspicious nodules on } \\
\text { GSUS }\end{array}$ \\
\hline Type 0 & $0 / 44$ & $8 / 46(17.4 \%)$ \\
Type 1 & $6 / 299(2 \%)$ & $34 / 142(24 \%)$ \\
Type 2 & $11 / 566(1.94 \%)$ & $77 / 329(23.4 \%)$ \\
Type 3 & $1 / 25(4 \%)$ & $23 / 51(45 \%)$ \\
& $18 / 934(1.9 \%)$ & $142 / 568(25 \%)$ \\
\hline
\end{tabular}

\section{DISCUSSION}

Some characteristics of the study deserve to be highlighted. The design was prospective and a large number of nodules $(\mathrm{n}=1,502)$ were analyzed. The nature of the nodules was defined by cytology or histology in > $99 \%$ of lesions. The nodules were selected according to current practice, in which FNA is recommended excep- tionally for nodules $<1 \mathrm{~cm}(1-7)$. The two classifications most frequently used to define the type of nodule vascularity were evaluated $(1,2,5-7,12,13,17)$. Instead of analyzing only the performance of Doppler US for the differentiation of benign and malignant nodules, its additional contribution to GSUS was also evaluated, since the latter is always obtained and its value has been well established. In addition, the rate of malignancy (approximately 10\%) is in accordance with that observed in subjects with nodular thyroid disease (1,3$5,12,13)$, minimizing the probability that the predictive values obtained are under- or overestimated.

In the present study, the absence of blood flow was uncommon (only $5 \%$ of the nodules), probably because of the characteristics of the nodules studied $(\geq 10 \mathrm{~mm}$ and solid). The expertise of the examiners may have also contributed to this finding. Grouping nodules with central flow, regardless of peripheral flow (first classification), the risk of malignancy was not higher in this group when compared to nodules without detectable flow or with exclusively peripheral flow. The risk of malignancy was only higher when predominantly or exclusively central flow was considered (second classification), although this flow was seen in only $15 \%$ of malignant nodules. Anyway, the second classification evaluated in this study provided better results. The Society of Radiologists in Ultrasound (1), French Society of Endocrinology (13) and Brazilian Society of Endocrinology (6) adopt a similar classification; however, we emphasize that the first classification is still used in the recommendations of the American Thyroid Association (2), American Association of Clinical Endocrinologists and European Thyroid Association (12), European Society for Medical Oncology (5), and National Comprehensive Cancer Network (7).

Even considering the second classification, we found no additional value of Doppler US to GSUS. In terms of clinical practice, two findings should be highlighted. First, only $2.7 \%$ of non-suspicious nodules on GSUS exhibited suspicious vascularity on Doppler US and the risk of malignancy of these nodules continued to be low. Second, among suspicious nodules on GSUS, although suspicious vascularity on Doppler US had increased the risk of malignancy, this risk remained high even in the absence of suspicious vascularity. Therefore, Doppler US did not change the indication for FNA based only on GSUS. In fact, many studies showing the usefulness of Doppler US analyzed its separate performance, but did not evaluate its additional value to GSUS (18). 
Some factors can affect the performance of Doppler US. Power Doppler imaging is more sensitive in detecting the slow flow of small vessels and is more specific than color Doppler (19-21). It is important to use minimal probe pressure when evaluating superficial lesions to avoid obliteration of low-velocity blood flow. In addition, interobserver variability in describing blood flow in the nodule is possible. Power Doppler imaging was used in the present study and all radiologists were well aware of the effect of compression on Doppler US images. It should be noted that no blood flow was detected in only $5 \%$ of the nodules. Although previous studies have shown good interobserver agreement in the localization of nodule vascularity $(22,23)$, we randomly selected 15 patients with 20 nodules to be evaluated by all three examiners and agreement in the type of vascularity was obtained for these nodules in all assessments (unpublished data). Moreover, the sensitivity and specificity of Doppler US calculated for each examiner were identical (unpublished data). In fact, the prospective design of the study, pre-establishing the types of vascularity, contributed to these uniform results.

Suspicious blood flow might be less frequent in nodules < $10 \mathrm{~mm}(11,24,25)$; as a consequence, there would be no reason to imagine that the contribution of Doppler US found in the present study (in nodules $\geq$ $10 \mathrm{~mm}$ ) is greater for infracentimetric nodules. In addition, the indications for FNA are highly selective in the latter case (1-7) and the evaluation of nodules $>10 \mathrm{~mm}$ is of greater practical applicability. We evaluated only solid or predominantly solid nodules. Since mixed nodules show a lower risk of malignancy $(1,4,12,13,17)$, it is unlikely that Doppler US is more useful in the case of these nodules.

In our study, 92.5\% (148 of 160) of malignancies were papillary thyroid carcinoma (PTC). Our study thus predominantly reflects the vascularity of PTC. However, we emphasize that the PTC accounts for up to $95 \%$ of differentiated thyroid carcinomas. In recent large series, even in nodules with "follicular neoplasm" or "follicular lesion of undetermined significance" cytology, $85 \%$ of malignant nodules were PTC $(26,27)$. The classical and limited differential diagnosis between adenoma and follicular carcinoma is no longer appropriate for current cases of indeterminate cytology. In fact, the criteria for differentiating benign and malignant thyroid nodules and for recommending FNA are thus weighted for detecting
PTC $(1-7,12,13,17)$. There is report that central flow is significantly associated with malignancy in follicular neoplasm, but did not evaluate its additional value to GSUS (18).

The vascularity, resistance index or pulsatility index was not quantified; only the pattern of vascularity was evaluated. No recommendations for the use of these parameters or objective cut-off values exist for predicting the malignancy of thyroid nodule $(1-7,12,13,17)$.

In the present study, Doppler US provided no additional value to GSUS in defining the nature of thyroid nodules.

Disclosure: no potential conflict of interest relevant to this article was reported.

\section{REFERENCES}

1. Frates $\mathrm{MC}$, Benson CB, Charboneau JW, Cibas ES, Clark $\mathrm{OH}$, Coleman BG, et al. Management of thyroid nodules detected at US: Society of Radiologists in Ultrasound consensus conference statement. Radiology. 2005;237:794-800.

2. Cooper DS, Doherty GM, Haugen BR, Kloos RT, Lee SL, Mandel SJ, et al. Revised American Thyroid Association management guidelines for patients with thyroid nodules and differentiated thyroid cancer. Thyroid. 2009;19:1167-214.

3. Camargo R, Corigliano S, Friguglietti C, Gauna A, Harach R, Munizaga $F$, et al. Latin American Thyroid Society recommendations for the management of thyroid nodules. Arq Bras Endocrinol Metabol. 2009;53:1167-75.

4. Moon WJ, Baek JH, Jung SL, Kim DW, Kim EK, Kim JY, et al. UItrasonography and the ultrasound-based management of thyroid nodules: consensus statement and recommendations. Korean J Radiol. 2011;12:1-14.

5. Pacini F, Castagna MG, Brilli L, Pentheroudakis G. Thyroid cancer: ESMO Clinical Practice Guidelines for diagnosis, treatment and follow-up. Ann Oncol. 2012;23(suppl 7):110-9.

6. Rosário PW, Ward LS, Carvalho GA, Graf H, Maciel RM, Maciel LM, et al. Thyroid nodules and differentiated thyroid cancer: update on the Brazilian consensus. Arq Bras Endocrinol Metabol. 2013;57:240-64.

7. Tuttle RM, Haddad RI, Ball DW, Byrd D, Dickson P, Duh QY, et al. Thyroid carcinoma, version 2.2014. J Natl Compr Canc Netw. 2014;12:1671-80.

8. Rago T, Vitti P, Chiovato L, Mazzeo S, De Liperi A, Miccoli P, et al. Role of conventional ultrasonography and color flow-Doppler sonography in predicting malignancy in 'cold' thyroid nodules. Eur J Endocrinol 1998;138:41-6.

9. Iannuccilli JD, Cronan JJ, Monchik JM. Risk for malignancy of thyroid nodules as assessed by sonographic criteria: the need for biopsy. J Ultrasound Med. 2004;23:1455-64.

10. Tamsel S, Demirpolat G, Erdogan M, Nart D, Karadeniz M, Uluer $\mathrm{H}$, et al. Power Doppler US patterns of vascularity and spectral Doppler US parameters in predicting malignancy in thyroid nodules. Clin Radiol. 2007;62:245-51.

11. Moon HJ, Kwak JY, Kim MJ, Son EJ, Kim EK. Can vascularity at power Doppler US help predict thyroid malignancy? Radiology. 2010;255:260-9. 
12. Gharib H, Papini E, Paschke R, Duick DS, Valcavi R, Hegedüs L, et al. American Association of Clinical Endocrinologists, Associazione Medici Endocrinologi, and European Thyroid Association Medical Guidelines for Clinical Practice for the Diagnosis and Management of Thyroid Nodules. Endocr Pract. 2010;16 (Suppl 1):1-43.

13. Wémeau JL, Sadoul JL, d'Herbomez M, Monpeyssen H, Tramalloni J, Leteurtre E, et al. Guidelines of the French society of endocrinology for the management of thyroid nodules. Ann Endocrinol (Paris). 2011;72:251-81.

14. Papini E, Guglielmi R, Bianchini A, Crescenzi A, Taccogna S, Nardi $F$, et al. Risk of malignancy in nonpalpable thyroid nodules: predictive value of ultrasound and color-Doppler features. J Clin Endocrinol Metab. 2002;87:1941-6.

15. Frates MC, Benson CB, Doubilet PM, Cibas ES, Marqusee E. Can color Doppler sonography aid in the prediction of malignancy of thyroid nodules? J Ultrasound Med. 2003;22:127-31.

16. De Nicola H, Szejnfeld J, Logullo AF, Wolosker AM, Souza LR, Chiferi V Jr. Flow pattern and vascular resistive index as predictors of malignancy risk in thyroid follicular neoplasms. J Ultrasound Med. 2005;24:897-904.

17. Perros P, Boelaert K, Colley S, Evans C, Evans RM, Gerrard Ba $\mathrm{G}$, et al. Guidelines for the management of thyroid cancer. Clin Endocrinol (Oxf). 2014;81(Suppl 1):1-122.

18. lared W, Shigueoka DC, Cristófoli JC, Andriolo R, Atallah AN, Ajzen SA, et al. Use of color Doppler ultrasonography for the prediction of malignancy in follicular thyroid neoplasms: systematic review and meta-analysis. J Ultrasound Med. 2010;29:419-25.

19. Spiezia S, Cerbone G, Colao A, Assanti AP, Picone GM, Lombardi G. Usefulness of power Doppler in the diagnostic management of hypoechoic thyroid nodules. Eur J Ultrasound. 1997;6:165-70.
20. Cerbone G, Spiezia S, Colao A, Di Sarno A, Assanti AP, Lucci R, et al. Power Doppler improves the diagnostic accuracy of color Doppler ultrasonography in cold thyroid nodules: follow-up results. Horm Res. 1999;52:19-24.

21. Lebkowska U, Dzieciol J, Jurgilewicz D, Laszkiewicz J. Power Doppler as a method that is better than color Doppler for evaluation of thyroid nodular lesions. Wiad Lek. 2001;54(Suppl 1):31-5.

22. Wienke JR, Chong WK, Fielding JR, Zou KH, Mittelstaedt CA. Sonographic features of benign thyroid nodules: interobserver reliability and overlap with malignancy. $\mathrm{J}$ Ultrasound Med. 2003;22:1027-31.

23. Choi SH, Kim EK, Kwak JY, Kim MJ, Son EJ. Interobserver and intraobserver variations in ultrasound assessment of thyroid nodules. Thyroid. 2010;20:167-72.

24. Cappelli C, Castellano M, Pirola I, Cumetti D, Agosti B, Gandossi $E$, et al. The predictive value of ultrasound findings in the management of thyroid nodules. QJM. 2007;100:29-35.

25. Popowicz B, Klencki M, Lewiński A, Slowińska-Klencka D. The usefulness of sonographic features in selection of thyroid nodules for biopsy in relation to the nodule's size. Eur J Endocrinol. 2009;161:103-11.

26. Rago T, Di Coscio G, Basolo F, Scutari M, Elisei R, Berti P, et al. Combined clinical, thyroid ultrasound and cytological features help to predict thyroid malignancy in follicular and Hürthle cell thyroid lesions: results from a series of 505 consecutive patients. Clin Endocrinol (Oxf). 2007;66:13-20.

27. Rago T, Scutari M, Latrofa F, Loiacono V, Piaggi P, Marchetti I, et al. he large majority of 1520 patients with indeterminate thyroid nodule at cytology have a favorable outcome, and a clinical risk score has a high negative predictive value for a more cumbersome cancer disease. J Clin Endocrinol Metab. 2014;99(10):3700-7. 